\title{
Diabetes Case Reports
}

\section{Common Pathophysiological Issues in Diabetes and Dementia}

\section{Hiroshi Bando}

Medical Research/ Tokushima University, Tokushima, Japan

*Corresponding author: Bando H, Medical Research/Tokushima University, School of Medicine, Tokushima, Japan, Tel: +819031872485; E-mail: pianomed@bronze.ocn.ne.jp

Rec Date: June 26, 2018, Acc Date: July 17, 2018, Pub Date: July 19, 2018

Copyright: $@ 2018$ Bando $\mathrm{H}$. This is an open-access article distributed under the terms of the Creative Commons Attribution License, which permits unrestricted use, distribution, and reproduction in any medium, provided the original author and source are credited.

\section{Commentary}

Recent medical problems in elderly people include dementia and metabolic syndrome such as diabetes and impaired glucose tolerance. Both are not different disease, but has common pathophysiological basis including glucose and ketone bodies and insulin resistance. Such topics would be described in this article.

Firstly, there have been various topics concerning brain and glucose, protein and fat. As brain uses glucose as main energy source, carbohydrate is necessary for ordinary function. Brain is only $2 \%$ of weight in the body, but it consumes about $25 \%$ of total glucose energy [1]. In contrast, excess consumption of glucose for long may cause decreased synaptic plasticity and increased inflammation, leading to probable cognitive impairment [2]. According to decreased sensitivity of brain for insulin with age, neuronal glucose utilization would gradually decrease with impaired cognitive function $[3,4]$.

As a role of dietary protein, it is important to supply amino acids for necessary neurotransmitters, such as serotonin and catecholamines [5]. Especially, tryptophan, precursor of serotonin and essential amino acid would have important role in human. It includes cognitive function, information processing and feeling the mood.

There is a blood brain barrier (BBB) in human for protecting neural system. Serotonin itself cannot pass the BBB, while tryptophan can enter $\mathrm{BBB}$ through specialized channels with conversion to 5hydroxyl-tryptophan (5-HTP) and lastly converted to serotonin [6]. Serotonin level would be decreased with age, probably influencing cognitive level $[5,7]$.

Dietary fat is necessary for the brain, because of the structure of neuronal membranes [5]. There are rich in poly unsaturated omega 3 fatty acids (PUFA) in all neurons. Omega- 3 fatty acids have been in focus, because it occupies approximately $30 \%$ of the membrane phospholipid composition. Especially, the omega-3 fatty acid docosahexaenoic acid (DHA) has been in considerable interest. It includes providing membrane fluidity and synaptic integrity, leading to affecting cognitive function [8]. Furthermore, MRI study showed that DHA scan may contribute for brain protection for aging process [9].

As mentioned above, research among three macronutrients and cognitive function has been progressing for many years. Among them, detail balance of major- and micro-nutrients seemed to be necessary for the proper function for brain [10]. In elderly people, appropriate changes in ordinary diet would be effective on cognitive function with reducing dementia [11]. One example is the Mediterranean diet, which is a standard meal for people living around the Mediterranean Sea. It is mainly composed of fresh seafood, red wine, bread, pasta, fruit, vegetables, olive oil $[12,13]$. People on Mediterranean diet seem to retain cognitive function [14].
Secondly, impressive reports were found about cognitive and diet. An intervention study was found, which was Finish Geriatric Intervention Study to Prevent Cognitive Impairment and Disability (FINGER). It included exercise, cognitive training, balanced meal of macronutrients with less than $10 \%$ of carbohydrate [15]. With such a multimodal approach, decreasing the rate of cognitive decline in the elderly cohort was successful [16].

As described above, the common point of Mediterranean meal and FINGER is characterized by rather high intakes of fruits, vegetables and whole grains, as well as low added sugar intake. Both diets can be compared. FINGER is based on Finish Nutritional Recommendations, developed based on a strict set of specific nutrition guidelines [17]. In contrast, the Mediterranean pattern is not as strict as the nutritional guidelines, and the food intake restriction is loose [18].

Another difference is the origin of food lipids. FINGER uses rapeseed oil, vegetables, margarine, while Mediterranean style uses olive oil and nuts. People on the Mediterranean will consume much amount of legume that affects the proportion of animals and plant proteins, besides the amount of fiber and phytic acid. Furthermore, moderate intake of red wine and resveratrol source is recommended for Mediterranean diet [19].

Clinically, the pathophysiological background is different between young and elderly people. In the former one cause can be usually speculated, but in the latter multifactorial possibility due to various tissues damage would be present. Therefore, dementia including Alzheimer's disease $(\mathrm{AD})$ draws the same trajectory as other related disorders and diseases. The mortality rate and the effect of age on $\mathrm{AD}$ are similar, the mortality rate doubles every 7.5 years from 30 -yearsold, and dementia doubles every 5 years [20]. Dementia is also closely related to multiple prevalence of diseases and frailty/locomotion syndrome [21].

Thirdly, the metabolism of ketone bodies and glucose has been in focus. Glucose is the brain's principal energy substrate. AD seems to have a pathological decrease in the brain's ability to use glucose. Due to the study of very low carbohydrate, ketogenic diet was effective for memory improvement in older adults with AD risk [22]. Its improved neurocognitive function would be supposed from correction of hyperinsulinemia, hyperketonemia, reduced inflammation and enhanced energy metabolism.

In the aged rats, ketogenic diet improved cognitive performance under normoxic and hypoxic conditions [23]. These data suggested that diet-induced ketosis may be beneficial for neurodegenerative conditions [23].

In clinical application, elevated ketone bodies $(\mathrm{KB})$ through an oral dose of medium chain triglycerides (MCTs) may improve cognitive functioning in older adults with memory disorders [24-26]. In addition, higher $\mathrm{KB}$ was associated with greater improvement in 
paragraph recall with MCT treatment relative to placebo across all subjects [26]. There was a report that the derivative of 3hydroxybutyrate (3HB), 3-hydroxybutyrate methyl ester (HBME) was used by cells as an alternative to glucose [27]. As a result, HBME inhibited cell apoptosis under glucose deprivation, rescued activities of mitochondrial respiratory chain complexes that were impaired in $\mathrm{AD}$ [27].

Finally, recent topics include diabetes and ketogenic diet, as well as $\mathrm{KB}$ and beneficial effect of KB. Author and colleagues have continued clinical research about KB, Low Carbohydrate Diet (LCD) and Calorie restriction (CR) [28-30]. As to the oxidation of the substrate, CR has rather incomplete oxidation from glucose metabolism, while LCD has rather complete oxidation from KB metabolism [31].

Regarding hyperglycemia in diabetes, advanced glycation end products (AGEs) has been in focus, which are the conjugation of glucose and protein [32]. They cause diabetic macro-angiopathy, micro-angiopathy, arteriosclerosis including dementia and various impaired function [32].

In summary, several related topics among cognitive problem, glucose, ketone bodies and macronutrients were described in this article. We expect further development of clinical study for correlation among glucose and $\mathrm{KB}$, diabetes and dementia in the future.

\section{References}

1. Sokoloff L (1999) Energetics of functional activation in neural tissues. Neurochem Res 24: 321-329.

2. Stefanidis A, Watt MJ (2012) Does too much sugar make for lost memories? J Physiol 590: 3633-3634.

3. Galeffi F, Shetty PK, Sadgrove MP, Turner DA (2015) Age-related metabolic fatigue during low glucose conditions in rat hippocampus. Neurobiol Aging 36: 982-992.

4. Ryu SY, Coutu JP, Rosas HD, Salat DH (2014) Effects of insulin resistance on white matter microstructure in middle-aged and older adults. Neurol 82: 1862-1870.

5. Bourre JM (2006) Effects of nutrients (in food) on the structure and function of the nervous system: Update on dietary requirements for brain. Part 2: macronutrients. J Nutr Health Aging 10: 386-399.

6. Shabbir F, Patel A, Mattison C, Bose S, Krishnamohan R, et al. (2013) Effect of diet on serotonergic neurotransmission in depression. Neurochem Int. 62: 324-329.

7. Melancon MO, Lorrain D, Dionne IJ (2014) Exercise and sleep in aging: Emphasis on serotonin. Pathol Biol (Paris) 62: 276-283.

8. Sidhu VK, Huang BX, Desai A, Kevala K, Kim HY (2016) Role of DHA in aging-related changes in the mouse brain synaptic plasma membrane proteome. Neurobiol Age 41: 73-85.

9. Denis I, Potier B, Heberden C, Vancassel S (2015) Omega-3 poly unsaturated fatty acids and brain aging. Curr Opin Clin Nutr Metab Care 18: 139-146.

10. Mallidou A, Cartie M (2015) Nutritional habits and cognitive performance of older adults. Nurs Manag (Harrow) 22: 27-34.

11. Hardman RJ, Kennedy G, Macpherson H, Scholey AB, Pipingas A (2015) A randomized controlled trial investigating the effects of Mediterranean diet and aerobic exercise on cognition in cognitively healthy older people living independently within aged care facilities: The Lifestyle Intervention in Independent Living Aged Care (LIILAC). study protocol Nutr J 14: 53.

12. Castro-Quezada I, Román-Vi nas B, Serra-Majem L (2014) The Mediterranean diet and nutritional adequacy: A review. Nutrients 6: 231.
13. Yannakoulia M, Kontogianni M, Scarmeas N (2015) Cognitive health and Mediterranean diet: Just diet or lifestyle pattern? Ageing Res Rev 20: 74-78.

14. Huhn S, Kharabian MS, Stumvoll M, Villringer A, Witte AV (2015) Components of a mediterranean diet and their impact on cognitive functions in aging. Front Aging Neurosci 7: 132.

15. Kivipelto M, Solomon A, Ahtiluoto S, Ngandu T, Lehtisalo J, et al. (2013) The Finnish geriatric intervention study to prevent cognitive impairment and disability (FINGER): Study design and progress. Alzheimers Dement 9: 657-665.

16. Ngandu T, Lehtisalo J, Solomon A, Levälahti E, Ahtiluoto S, et al. (2015) A 2-year multi domain intervention of diet, exercise, cognitive training, and vascular risk monitoring versus control to prevent cognitive decline in at-risk elderly people (FINGER): A randomized controlled trial. Lancet 385: 2255-2263.

17. National Nutrition Council (2005) Finnish nutrition recommendations: Diet and physical activity in balance p: 57.

18. Woodside JV, Gallaghe NE, Neville CE, Kinley MC (2014) Mediterranean diet interventions to prevent cognitive decline-opportunities and challenges. Eur J Clin Nutr 68: 1241-1244.

19. Huhn S, Kharabian Masouleh S, Stumvoll M, Villringer A, Witte AV (2015) Components of a Mediterranean diet and their impact on cognitive functions in aging. Front Aging Neurosci 7: 132.

20. Raber J, Huang Y, Ashford JW (2004) Apo E genotype accounts for the vast majority of $\mathrm{AD}$ risk and $\mathrm{AD}$ pathology. Neurobiol Aging 25: 641-650.

21. Oosterveld SM, Kessels RP, Hamel R, Ramakers IH, Aalten P, et al. (2014) The influence of Co-morbidity and frailty on the clinical manifestation of patients with Alzheimer's disease. J Alzheimers Dis 42: 501-509.

22. Krikorian R, Shidler MD, Dangelo K, Couch SC, Benoit SC (2012) Dietary ketosis enhances memory in mild cognitive impairment. Neurobiol Aging 33: 19-27.

23. Xu K, Sun X, Eroku BO, Tsipis CP, Puchowicz MA, et al. (2010) Dietinduced ketosis improves cognitive performance in aged rats. Adv Exp Med Biol 662: 71-75.

24. Shimazu T, Hirschey MD, Newman J, He W, Shirakawa K, et al. (2013) Suppression of oxidative stress by $\beta$-hydroxybutyrate, an endogenous histone deacetylase inhibitor. Science 339: 211-214.

25. Gräff J, Tsai LH (2013) The potential of HDAC inhibitors as cognitive enhancers. Annu Rev Pharmacol Toxicol 53: 311-330.

26. Reger MA, Henderson ST, Hale C, Cholerton B, Baker LD, et al. (2004) Effects of beta-hydroxybutyrate on cognition in memory-impaired adults. Neurobiol Aging 25: 311-314.

27. Zhang J, Cao Q, Li S, Lu X, Zhao Y, et al. (2013) 3-Hydroxybutyrate methyl ester as a potential drug against Alzheimer's disease via mitochondria protection mechanism. Biomaterials 34: 7552-7562.

28. Bando H, Ebe K, Manabe T, Bando M, Yonei Y (2018) Less carbohydrate intake increases serum ketone bodies in low carbohydrate diet. Endocrinol Metab 2: 9.

29. Ebe K, Bando H, Yamamoto K, Bando M, Yonei Y (2018) Daily carbohydrate intake correlates with $\mathrm{HbAlc}$ in low carbohydrate diet (LCD). J Diabetol 1: 4-9.

30. Muneta T, Kawaguchi E, Nagai Y, Matsumoto M, Ebe K, et al. (2016) Ketone body elevation in placenta, umbilical cord, newborn and mother in normal delivery. Glycative Stress Res 3: 133-140.

31. Zhang Y, Kuang Y, La Manna JC, Puchowicz MA (2013) Contribution of brain glucose and ketone bodies to oxidative metabolism. Adv Exp Med Biol 765: 365-370.

32. Yagi M, Yonei Y (2016) Glycative stress and anti-aging: What is glycative stress? Glycative Stress Res 3: 152-155. 